\title{
Ultrasound Characterization of a Solitary Thyroid Nodule According to British Thyroid Association (BTA) - Derived Criteria: A Simple Test of Reliability on a Small Cohort
}

\author{
LAMYA A. EISSA, M.D.*; NOORALDEEN ALSAMAHI, M.S.*; MOHAMED SAMY BARAKAT, M.D.*; \\ DINA ABDALLAH, M.D.** and MUHAMMED MAHMOUD EL-SHAFEI, M.D.*
}

The Department of Diagnostic \& Interventional Radiology* and Department of Pathology**, Alexandria Faculty of Medicine, Alexandria, Egypt

\begin{abstract}
Background: US-based thyroid imaging lexicons have been widely used in clinical practice for identification of FNAC-eligible thyroid nodules. A "U"-classification (BTA) was introduced in 2014 with intense researches conducted in last five years trying to test its feasibility and reliability in stratification of US thyroid nodules.
\end{abstract}

Material and Methods: Prospective single-center unidepartmental study aimed at selection of only "solitary" nodules with image-analysis of US features of suspicious and non-suspicious nodules and ascribing each nodule a "U"-class in view of lexicon-provided user-friendly graphic references.

Results: A small cohort, of 37 solitary nodules, was selected out of a total of 150 with comparison to FNAC aspiration cytology result according to pathology Bethesda staging. The correlation of each " $U$ " class was compared to pathology (fine needle aspirates) and revealed very good statistical significance.

Conclusion: The study suggests that a BTA (The "U"classification) is a simple reliable test that can be feasibly practiced to select FNAC-eligible nodule amongst multinodular glands.

Key Words: Ultrasound characterization - British Thyroid Association (BTA) - Solitary Thyroid.

\section{Introduction}

THYROID nodules are very common in adults, especially in women [1]. The clinical prevalence is reaching about $4 \%-7 \%$, but the widespread use of ultrasound (US) has increased the overall prevalence to reach about 67\% [1-5]. Ultrasonography (US), the imaging modality of choice, is a noninvasive, widely available and non-expensive technique that does not impose any hazardous ionizing radiation [6-9]. Suspicious US features may be

Correspondence to: Dr. Lamya Eissa

E-Mail: lamya.eissa@gmail.com useful for choosing candidate patients for fineneedle aspiration cytology (FNAC). A number of different US classification systems evolved in a trial to differentiate benign from malignant nodules and to help to stratify the degree of suspicion. In 2009 , Horvath was the first one to describe TIRADS as a stratification method for the risk of cancer in thyroid nodules and thus nodule selection [10-14]. This system is a kind of "scoring" system where malignancy risk rises with the increase of the number of suspicious US features [15]. Another version of TI-RADS was proposed by the ACR in order to decrease the number of FNAs on noneligible nodules, thus decreasing patient's anxiety and economic burden on health-care organizations [16]. It is also a kind of scoring system encompassing different "US" features and giving each nodule a suitable numerical score ( $=0-3$ points). Indications for FNA aspiration are based on "ACR"-TI-RADS level in addition to the maximal axial diameter of the thyroid nodule. Highly suspicious nodules are prepared to be biopsied only if they are $\geq 1 \mathrm{~cm}$, while low-risk nodules should be further investigated only when they are $>2.5 \mathrm{~cm}$. The main purpose of "ACR"-TI-RADS is to make a balance between the benefits of detecting clinically significant malignancies against the cost of submitting benign

\footnotetext{
List of Abbreviations:

AACE : American Association of Clinical Endocrinologists.

ACE : American College of Endocrinology.

AME : Associazione Medici Endocrinologi classification American Thyroid Association (ATA) classification British Thyroid Association (BTA) US classification of thyroid nodules.

FNAC : Fine needle aspiration cytology.

MDT : Multi-departmental team

US : Ultrasound.

UK : United Kingdom.
} 
nodules to invasive management. European (EU)TI-RADS is also a thyroid nodule classification system, and has been subsequently modified into an easier-to-use version, validated in a large crosssectional prospective studies in 2013, and finally published as a European guideline in year 2017 [17]. It is rather a scored class or grading system that shows five categories, each of which is further scored according to a number of US-features $[18,19,20]$. The Korean version "K-TI-RADS" system classifies the thyroid nodules as high suspicion, intermediate suspicion, low suspicion, and benign. The decision to perform FNA is based on the calculated malignancy risk according to the ultrasound features combined with nodular size, and yet with the exclusion of poor prognostic factors, such as lymph node metastasis, extra thyroidal tumor extension, or distant metastasis from thyroid cancer. Nodular vascularization and elastography features are considered useful in the differentiation of benign from malignant nodules, but these are not yet included in the classification and further studies are needed to elucidate their complementary function in the risk categories [20,21]

Several other combined American lexicons have been proposed by "AACE/ACE/ and AME", which were meant to stratify nodules into a 3-Class system based on their risks of malignancy (low, intermediate, and high risk) according to US features combined with nodule dimension and with the addition of patient's clinical history [22] .

The ATA classification is also a scoring system made to calculate risk of malignancy. However, in ATA, the color US-Doppler and elastosonographyderived parameters are completely excluded [22,23]

Despite strenuous efforts made in investigating different US features of thyroid and trials to compare different proposed classification systems, none of these classifications have been widely adopted worldwide, and there are still conflicting recommendations from several different societies. However, in the last few years, several studies have compared the different US risk stratifications systems in larger cohorts of patients with thyroid nodules in order to evaluate the most accurate and useful system $[\mathbf{1 , 2 1 , 2 2 , 2 4 ]}$.

Another promising system, developed by the British Thyroid Association (BTA), was introduced to the 2014 guidelines on the management of thyroid cancer. The recommendation aims to stratify thyroid nodules as benign, suspicious or malignant based on ultrasound appearances termed U1-U5
[25]. It considers the following US features as predictors of malignancy: Eccentric location of the solid portion in a partially cystic nodule, the nonsmooth margins, the hypo-echogenicity of the solid portion, micro-calcifications, and "Taller-thanwide" shape [24]. It provides simple graphic pictures that show how different morphologies (listed as "a" through "f"), and how each of them can be ascribed to certain U-class. These images are assumed to make it easier for more recognition of different morphological patterns and thus easier imaging practice. The system presents the morphological class with no numerical scoring system and size is not included in criteria [25]. These graphic references are supposed to encourage the sonographer to translate his findings into a particular degree of concern, thus allowing for a common "Thyroid language" among health care professionals to communicate ultrasound findings. However, there are some clinical and economic concerns regarding the guidelines, which may be controversial, and others that have limited applicability in day-today practice $[26,27]$. For example, mixed and internal vascularity in a nodule renders this nodule a class of $\mathrm{U} 3$ and $\mathrm{U} 5$ respectively, according to the BTA guidelines. Given that in real practice some degree of internal vascularity is a common finding while its presence is considered a somewhat 'softer' sonographic feature of malignancy according to guideline. Therefore if these criteria are strictly adhered to, that would likely lead to an increased amount of nodules labeled as 'indeterminate' (U3) and 'likely malignant' (U5) with the inherent risk of more unnecessary FNAs performed, more anxiety and potentially more unnecessary surgeries carried out [28-32].

\section{Material and Methods}

A- Study design: The study was made prospectively in adult patients referred to our university department for US of the thyroid gland. Inclusion criteria included the: (a) Adult population (>18 years), (b) Solitary thyroid nodule (by US). A solitary thyroid nodule is defined by Sonography not clinically. Selection of solitary nodule was made for a number of reasons: Firstly a non-biased selection of the nodule most indicated for USguided FNAC, since this is made in clinical practice in accordance with TIRADs, meanwhile selection by the lexicon under study can be confusing and biased. Secondly, easier methodology and easier, though less accurate, statistics can be made on smaller number of patients and nodules, as well as evading the confusion between number of nodules against the number of patients. Thirdly, in 
order to narrow the spectrum of indeterminate and suspicious nodules, being more prevalent amongst solitary nodules, with exclusion of the much more common multiple benign nodules. Exclusion criteria include: (a) Prior history of thyroid malignancy or history of radiation to the neck, (b) Children, (c) Multi-nodular goiter (clinically or US proved), and all other thyroid patients having more than one nodule. Approval for this study was obtained from the "Research Ethics Committee" of our general hospital. The study procedures are meant to be carried-out in accordance with the "Declaration of Helsinki" regarding research involving human subjects. Each patient included in the study was subjected to (a) Full history taking and (b) Clinical examination by head and neck or ENT surgeon.

B- Ultrasound examination, including: 2D ultrasound scan was made. Ultrasound examination, image acquisition and FNAC were performed at the time of each patient visit by an experienced head and neck radiologist (10 years' experience), using the 'Thyroid' presets and high-frequency linear probe $(6-15 \mathrm{MHz})$ on a General Electric (GE) LOGIC-E9 ultrasound scanner (GE Healthcare, Chicago, USA). All examinations were performed at a frequency between 9 and $13 \mathrm{MHz}$, with $1-2$ focal zones centered on the region of interest and with spatial compound (GE 'Cross-Beam') imaging enabled. In addition to B-Mode (Brightness-Mode) grey-scale images, color Doppler was used as a problem-solving tool in selected examinations. Where used, Doppler color-flow region of interest was limited to the nodule under investigation and the following parameters applied: Power (acoustic output) 14100 .

C-Image Analysis (Nodule analysis): Thyroid nodules are characterized according to the relevant nodule shape, margins, echo-texture, echogenicity, composition, calcifications, vascularity, comet tail artifact, echogenic foci, peripheral halo and lymphadenopathy: (a) The nodule shape is classified as wider than taller and taller than wider, (b) $\mathrm{He}$ nodule margins are classified as smooth/regular and lobulated/irregular, (c) The echo-texture patterns of the nodules were classified as homogenous and heterogeneous, (d) For echogenicity, they are classified as anechoic, markedly hypoechoic (compared to strap muscles), hypoechoic (compared to the thyroid gland), iso-echoic, mildly hyperechoic or markedly hyperechoic, (e) The nodule composition was classified as either solid, cystic, mixed solid and cystic or micro-cystic/spongiform, (f) For thyroid nodule with cystic change, the presence of ring down sign is evaluated and documents colloid, (g) Nodules with mixed components were evaluated on the basis of its solid component, (h) Calcifications, when present, their site categorized as central or peripheral and their shape as eggshell, globular or micro-calcifications, (i) The nodules are classified according to peripheral halo present or not, (j) According to vascularity, the nodules were classified as having central, peripheral, mixed or none vascularity, (k) Any suspiciously looking lymphadenopathy in the context of suspected malignancy shall be considered metastases. Suspicious lymph nodes is defined as size more than $10 \mathrm{~mm}$, loss of fatty hilum, rounded bulging shape, irregular margins, heterogeneous echo texture, calcifications, cystic areas or increased vascularity throughout the lymph node.

$D$ - Nodule " $U$ " Classification:These are made with reference to list and graphic pictures proposed by the "BTA". Refer to Fig. (1) [33] . (1) U1 (normal): No nodules, (2) U2 (benign): (a) Hyperechoic or iso-echoic with a halo, (b) Cystic change with ring down artifact (colloid), (c) Micro-cystic or spongiform appearance, (d) Incomplete peripheral egg-shell calcification, Complete peripheral eggshell calcification, (e) Peripheral vascularity, (3) U3 (indeterminate): (a) Solid homogenous markedly hyperechoic nodule with halo (follicular lesions), (b) Hypoechoic with equivocal echogenic foci or cystic change, (c) Mixed or central vascularity, (4) U4 (suspicious): (a) Solid hypoechoic (compared with thyroid), (b) Solid very hypoechoic (compared with strap muscles), (c) Hypoechoic with disrupted peripheral calcification, (d) Lobulated outline, (5) U5 (malignant): (a) Solid hypoechoic with a lobulated or irregular outline and micro-calcification (Papillary carcinoma), (b) Solid hypoechoic with a lobulated or irregular outline and globular calcification. (Medullary carcinoma), (c) Intra-nodular vascularity, (d) Taller than wide axially ( $\mathrm{AP}>\mathrm{ML}$ ), (e) Characteristic associated lymphadenopathy.

E- Pathological evaluation: US-guided FNAC aspiration will be performed in the examined nodules, and pathology will be reported according to Bethesda system (2001).

F- Statistical analysis: Statistical analysis was performed with the SPSS software package IBM version 23 . The main issue to be investigated is statistical significance of each US feature in predicting malignancy and significance of each $U$ as compared to FNAC cytology result. 


\section{Results}

The study enrolled 150 patients suspected to have thyroid nodules, either palpable or incidental during neck examination, or coming for their routine follow-up visits for a solitary nodule. Only thirty-seven patients were found to have a solitary nodule for both lobes. Sex and age demographics of patients revealed: 5 males $13.5 \%$ ) and 32 females $(86.5 \%)$. Their ages ranged from 27 to 65 years. Most patients' ages (Twenty one) $(56.8 \%)$ were between $>4$ and $\leq 60$ years old, then patients' ages ranged between 20 and 40 years old were 13 $(35.1 \%)$ and lastly patients' ages more than 60 years old were only $3(8.1 \%)$. Of the examined 37 patients, 14 patients $(37.84 \%)$ had malignant nodules and 23 patients $(62.16 \%)$ had benign nodules. Of patients with malignant nodules, two of five male patients had malignant thyroid nodules (14.3\% of all patients with malignant thyroid nodules) while 12 of 32 females had malignant thyroid nodules $(85.7 \%$ of all patients with malignant thyroid nodules).

For nodule analysis, results revealed: (A) Size (Only routine measurement): The mean size of nodules in all 37 patients was $2.57 \pm 1.42 \mathrm{~cm}$. (B) Shape: 34 of the 37 patients $(91.9 \%)$ had "wider than taller" thyroid nodules; 11 patients of them had malignant nodules representing $78.6 \%$ of all patients with malignant nodules. Three of the 37 patients $(8.1 \%)$ had "taller than wide" thyroid nodules; all of them were malignant nodules representing $21.4 \%$ of the total malignant nodules. Statistical analysis revealed that "taller than wider shape" of nodules to bear statistical significance in determination of malignant nature of thyroid nodules ( $p$-value $=0.047)$. (C) For the margins of thyroidnodules: (a) 31 nodules $(83.3 \%$ ) had smooth and regular margins, 8 of them proved malignant, representing $57.1 \%$ of all malignant thyroid nodules, (b) 6 nodules $(16.2 \%$ ) had irregular or lobulated margins; all of them were malignant, representing $42.9 \%$ of all patients with malignant thyroid nodules, (D) For the echo-texture of thyroid nodules: 27 nodules $(73 \%)$ revealed homogenous texture, 9 of them were malignant, representing $64.2 \%$ of all malignant nodules. 10 nodules $(27 \%)$ had heterogeneous texture, 5 of them were malignant nodules (representing $35.7 \%$ of all malignant thyroid nodules).

Statistical analysis: Revealed that margins of nodules (lobulated/irregular) had a statistical significance in determination of malignant nature of the thyroid nodules ( $p$-value $=0.001)$. In contrary, echo-texture didn't show statistical significance in determination of malignant or benign nature of thyroid nodules. (Table 1), (E) For the echogenicity of thyroid nodules (Table 2): Two nodules (5.4\%) were anechoic (cystic); none of them were malignant. Three nodules $(8.1 \%)$ were hypoechoic and proved to be malignant, representing $21.4 \%$ of malignant nodules. Nine nodules $(24.3 \%)$ had isoechoic thyroid nodules; only one of them had malignant nodule, representing $7.1 \%$ of all malignant nodules. One nodule $(2.7 \%)$ was hyperechoic and was found to be malignant, representing $7.1 \%$ of all malignant nodules. Thirteen $(35.1 \%)$ nodules were mildly hyperechoic; none of them were found to be malignant. Finally 9 nodules $(24.3 \%)$ were very hypoechoic; all of them were found to be malignant, representing $64.3 \%$ of malignant thyroid nodules. Statisticalanalysis revealed that: (a) US feature of being mildly hyperechoic had statistical significance in determining benign nature of thyroid nodules ( $p$-value <0.001), (b) US feature of being hypoechoic or very hypoechoic had statistical significance in determining malignant nature of thyroid nodules (Their $p$-values 0.047 and $<0.001$ respectively), (F) For the composition nature of thyroid nodules, of the 37 nodules: Two nodules (5.4\%) were cystic; none of them was malignant. One nodule $(2.7 \%)$ had f spongiform/microcytic appearance; also not found to be malignant. Eleven nodules $(29.7 \%)$ showed mixed solid and cystic nature; none of them were found to be malignant. Finally 23 nodules $(62.2 \%)$ had solid nature, 14 of them were found malignant. Statistical analysis revealed that being a nodule with mixed solid and cystic nature had statistical significance in determining benign nature of thyroid nodules ( $p$-value $=$ 0.002 ). Being a nodule with solid nature had statistical significance in determining malignant nature of thyroid nodules ( $p$-value <0.001). (Refer to Table 3), (G) For the calcification site in the thyroid nodules: Thirty nodules $(81.1 \%)$ had no calcifications; 8 of them were malignant, representing $57.1 \%$ of all malignancies. Five nodules (13.5\%) had central calcifications; all of them were malignant representing (35.7\% of all malignant nodules). Two nodules (5.4\%) had peripheral calcifications; one of them proved malignant thyroid nodule $(7.1 \%$ of all malignant nodules, for the calcification shape: (a) Micro calcifications defined as small $(<1 \mathrm{~mm})$ echogenic foci without acoustic shadowing, while (b) Coarse/globular calcifications are larger than $2 \mathrm{~mm}$ and may or may not cause posterior acoustic shadowing One nodule (2.7\%) had egg-shell calcification and benign. Two nodules (5.4\%) with globular calcifications; each nodule found to be malignant, representing (14.3\% of all malignant nodules). Four nodules (10.8\%) had micro- 
calcifications, and all these were found to be malignant, representing $28.6 \%$ of all malignant nodules. Statistical analysis revealed that being a nodule with no calcifications had statistical significance in determining benign nature of thyroid nodules $(p$-value $=0.007)$. Being a nodule with central calcification had statistical significance in determining malignant nature of thyroid nodules $(p$-value $=0.005)$. Being a nodule with microcalcification had statistical significance in determining malignant nature of thyroid nodules ( $p$ value $=0.015),(\mathrm{H})$ For the vascularity in the thyroid nodules: Five nodules (13.5\%) had no vascularity; none of them were malignant. Seventeen nodules (45.9\%) had mixed vascularity; seven of them were malignant (50\% of all malignant nodules). Four nodules $(10.8 \%)$ had intra-nodular vascularity; all of them were malignant nodules $(28.6 \%$ of all malignant nodules). Eleven nodules $(29.7 \%)$ had peripheral vascularity; three of them were found to be malignant (21.4\% of all malignant nodules). Statistical analysis revealed that being a nodule with intra-nodular vascularity had statistical significance in determining malignant nature of thyroid nodules ( $p$-value $=0.015)$. (I) Relation between other some US findings (comet tail/ring down artifact, echogenic foci and peripheral halo) and the pathological diagnosis: One nodule $(2.7 \%)$ had comet tail/ring down artifact and it proved as benign. Two nodules $(5.4 \%)$ had echogenic foci; one of them were malignant $(7.1 \%$ of malignant nodules). Twelve nodules (32.4\%) had peripheral halos; all of them proved to be benign. Statistical analysisrevealed that peripheral halo sign shows statistical significance in determination of benignity of the nodules $(p$-value $=0.001)$, while the other two signs (comet tail/ring down artifact and echo- genic foci) unexpectedly revealed no statistical significance in our study, (j) For the feature of associated" Sonographically" suspicious cervical lymph nodes: Thirty-fournodules $(91.9 \%)$ had no associated no suspect cervical lymph nodes. Three $(8.1 \%)$ had associated pathologically enlarged nodes; all of them were malignant nodules. Statistical analysis revealed that the ultrasound feature of associated Sonographically suspicious cervical lymph nodes had statistical significance in determining malignant nature of thyroid nodules ( $p$ value $=0.047)$, (k) Relation between U-classification system and the pathological diagnosis. Twelve out of 37 nodules $(32.4 \%)$ had ultrasound criteria matching with U2-group; all of them proved nodules. Twelve other nodules of the total 37 (32.4\%) had ultrasound criteria matching with U3 group; only one of them was malignant, representing $7.1 \%$ of all malignant nodules. Four of the total 37 nodules (10.8\%) had ultrasound criteria matching with U4 group; all of them were malignant, representing $28.6 \%$ of all malignant nodules. Nine out of the 37 nodules $(24.3 \%)$ had US criteria matching with U5 group; all of them were malignant nodules, representing $64.3 \%$ of all malignant nodules. Statistical analysis revealed that being a thyroid nodule with U2 ultrasound criteria had statistical significance in determining benign nature of thyroid nodules $(p$-value $=0.001)$. Being a thyroid nodule with U3-ultrasound criteria had statistical significance in determining benign nature of thyroid nodules $(p$-value $=0.013)$. Being a thyroid nodule with U4-class had statistical significance in determining malignant nature of thyroid nodules ( $p$ value $=0.15$ ). Being a thyroid nodule with U5 had a high statistical significance in determining malignant nature of thyroid nodules ( $p$-value $<0.001$ ).

Table (1): Comparison between the two studied groups (Benign and malignant) according to margins and echo-texture.

\begin{tabular}{|c|c|c|c|c|c|c|c|c|}
\hline & \multirow{2}{*}{\multicolumn{2}{|c|}{$\begin{array}{l}\text { Total } \\
(\mathrm{n}=37)\end{array}$}} & \multicolumn{4}{|c|}{ Final diagnosis } & \multirow{3}{*}{$x^{2}$} & \multirow{3}{*}{$\mathrm{FE}_{\mathbf{p}}$} \\
\hline & & & \multicolumn{2}{|c|}{$\begin{array}{l}\text { Benign } \\
(n=23)\end{array}$} & \multicolumn{2}{|c|}{$\begin{array}{c}\text { Malignant } \\
(\mathrm{n}=14)\end{array}$} & & \\
\hline & No. & $\%$ & No. & $\%$ & No. & $\%$ & & \\
\hline \multicolumn{9}{|l|}{ Margins/outlines: } \\
\hline Smooth/regular & 31 & 83.8 & 23 & 100.0 & 8 & 57.1 & $11.765^{*}$ & $0.001 *$ \\
\hline Lobulated/irregular & 6 & 16.2 & 0 & 0.0 & 6 & 42.9 & & \\
\hline \multicolumn{9}{|l|}{ Homo/hetero: } \\
\hline Homogenous & 27 & 73.0 & 18 & 78.3 & 9 & 64.3 & 0.862 & 0.454 \\
\hline Heterogeneous & 10 & 27.0 & 5 & 21.7 & 5 & 35.7 & & \\
\hline
\end{tabular}


Table (2): Comparison between the two studied groups (Benign and malignant) according to echogenicity.

\begin{tabular}{|c|c|c|c|c|c|c|c|c|}
\hline \multirow{3}{*}{ Echogenicity } & \multirow{2}{*}{\multicolumn{2}{|c|}{$\begin{array}{c}\text { Total } \\
(\mathrm{n}=37)\end{array}$}} & \multicolumn{4}{|c|}{ Final diagnosis } & \multirow{3}{*}{$x^{2}$} & \multirow{3}{*}{$\mathrm{FE}_{\mathbf{p}}$} \\
\hline & & & \multicolumn{2}{|c|}{$\begin{array}{l}\text { Benign } \\
(n=23)\end{array}$} & \multicolumn{2}{|c|}{$\underset{(n=14)}{\operatorname{Malignant}}$} & & \\
\hline & No. & $\%$ & No. & $\%$ & No. & $\%$ & & \\
\hline Anechoic & 2 & 5.4 & 2 & 8.7 & 0 & 0.0 & 1.287 & 0.517 \\
\hline $\begin{array}{l}\text { Hypoechoic } \\
\text { (compared to thyroid gland) }\end{array}$ & 3 & 8.1 & 0 & 0.0 & 3 & 21.4 & $5.363^{*}$ & $0.047 *$ \\
\hline Isoechoic & 9 & 24.3 & 8 & 34.8 & 1 & 7.1 & 3.612 & 0.112 \\
\hline Markedly hyperechoic & 1 & 2.7 & 0 & 0.0 & 1 & 7.1 & 1.688 & 0.378 \\
\hline Mildly hyperechoic & 13 & 35.1 & 13 & 56.5 & 0 & 0.0 & $12.199 *$ & $<0.001 *$ \\
\hline $\begin{array}{l}\text { Very hypoechoic } \\
\text { (compared to strap ms) }\end{array}$ & 9 & 24.3 & 0 & 0.0 & 9 & 64.3 & $19.538 *$ & $<0.001 *$ \\
\hline
\end{tabular}

Table (3): Comparison between the two studied groups (Benign and malignant) according to composition nature.

\begin{tabular}{|c|c|c|c|c|c|c|c|c|}
\hline \multirow{3}{*}{ Solid vs. cystic } & \multirow{2}{*}{\multicolumn{2}{|c|}{$\begin{array}{c}\text { Total } \\
(\mathrm{n}=37)\end{array}$}} & \multicolumn{4}{|c|}{ Final diagnosis } & \multirow{3}{*}{$x^{2}$} & \multirow{3}{*}{$p$} \\
\hline & & & \multicolumn{2}{|c|}{$\begin{array}{l}\text { Benign } \\
(n=23)\end{array}$} & \multicolumn{2}{|c|}{$\begin{array}{l}\text { Malignant } \\
(\mathrm{n}=14)\end{array}$} & & \\
\hline & No. & $\%$ & No. & $\%$ & No. & $\%$ & & \\
\hline Cyst & 2 & 5.4 & 2 & 8.7 & 0 & 0.0 & 1.287 & $\mathrm{FE}_{\mathrm{p}}=0.517$ \\
\hline Micro-cystic/spongiform & 1 & 2.7 & 1 & 4.3 & 0 & 0.0 & 0.626 & $\mathrm{FE}_{\mathrm{p}=1.000}$ \\
\hline Solid & 23 & 62.2 & 9 & 39.1 & 14 & 100.0 & $13.709 *$ & $<0.001^{*}$ \\
\hline Solid with cystic changes & 11 & 29.7 & 11 & 47.8 & 0 & 0.0 & $9.528^{*}$ & $\mathrm{FE}_{\mathrm{p}=0.002 *}$ \\
\hline
\end{tabular}

Table (4): Comparison between the studied groups according (Benign and malignant) to calcification site and shape.

\begin{tabular}{|c|c|c|c|c|c|c|c|c|}
\hline & \multirow{2}{*}{\multicolumn{2}{|c|}{$\begin{array}{c}\text { Total } \\
(\mathrm{n}=37)\end{array}$}} & \multicolumn{4}{|c|}{ Final diagnosis } & \multirow{3}{*}{$x^{2}$} & \multirow{3}{*}{$\mathrm{FE}_{\mathbf{p}}$} \\
\hline & & & \multicolumn{2}{|c|}{$\begin{array}{l}\text { Benign } \\
(\mathrm{n}=23)\end{array}$} & \multicolumn{2}{|c|}{$\begin{array}{l}\text { Malignant } \\
(\mathrm{n}=14)\end{array}$} & & \\
\hline & No. & $\%$ & No. & $\%$ & No. & $\%$ & & \\
\hline \multicolumn{9}{|l|}{ Calcification site: } \\
\hline None & 30 & 81.1 & 22 & 95.7 & 8 & 57.1 & $8.413^{*}$ & $0.007 *$ \\
\hline Central & 5 & 13.5 & 0 & 0.0 & 5 & 35.7 & $9.498^{*}$ & $0.005 *$ \\
\hline Peripheral & 2 & 5.4 & 1 & 4.3 & 1 & 7.1 & 0.133 & 1.000 \\
\hline \multicolumn{9}{|l|}{ Calcification shape: } \\
\hline None & 30 & 81.1 & 22 & 95.7 & 8 & 57.1 & $8.413^{*}$ & $0.007 *$ \\
\hline Egg-shell & 1 & 2.7 & 1 & 4.3 & 0 & 0.0 & 0.626 & 1.000 \\
\hline Globular & 2 & 5.4 & 0 & 0.0 & 2 & 14.3 & 3.473 & 0.137 \\
\hline Micro-calcification & 4 & 10.8 & 0 & 0.0 & 4 & 28.6 & $7.368^{*}$ & $0.015 *$ \\
\hline
\end{tabular}

Table (5): Comparison between the two studied groups (Benign and malignant) according to vascularity.

\begin{tabular}{|c|c|c|c|c|c|c|c|c|}
\hline \multirow{3}{*}{ Vascularity } & \multirow{2}{*}{\multicolumn{2}{|c|}{$\begin{array}{l}\text { Total } \\
(\mathrm{n}=37)\end{array}$}} & \multicolumn{4}{|c|}{ Final diagnosis } & \multirow{3}{*}{$x^{2}$} & \multirow{3}{*}{$p$} \\
\hline & & & \multicolumn{2}{|c|}{$\begin{array}{l}\text { Benign } \\
(n=23)\end{array}$} & \multicolumn{2}{|c|}{$\begin{array}{c}\text { Malignant } \\
(\mathrm{n}=14)\end{array}$} & & \\
\hline & No. & $\%$ & No. & $\%$ & No. & $\%$ & & \\
\hline None & 5 & 13.5 & 5 & 21.7 & 0 & 0.0 & 3.519 & $\mathrm{FE}_{\mathrm{p}=0.135}$ \\
\hline Mixed & 17 & 45.9 & 10 & 43.5 & 7 & 50.0 & 0.149 & 0.699 \\
\hline Intra-nodular & 4 & 10.8 & 0 & 0.0 & 4 & 28.6 & $7.368 *$ & $\mathrm{FE}_{\mathrm{p}=0.015^{*}}$ \\
\hline Peripheral & 11 & 29.7 & 8 & 34.8 & 3 & 21.4 & 0.743 & $\mathrm{FE}_{\mathrm{p}=0.477}^{\mathrm{r}}$ \\
\hline
\end{tabular}


Table (6): Comparison between the two studied groups (Benign and malignant) according to $\mathrm{U}$ classification.

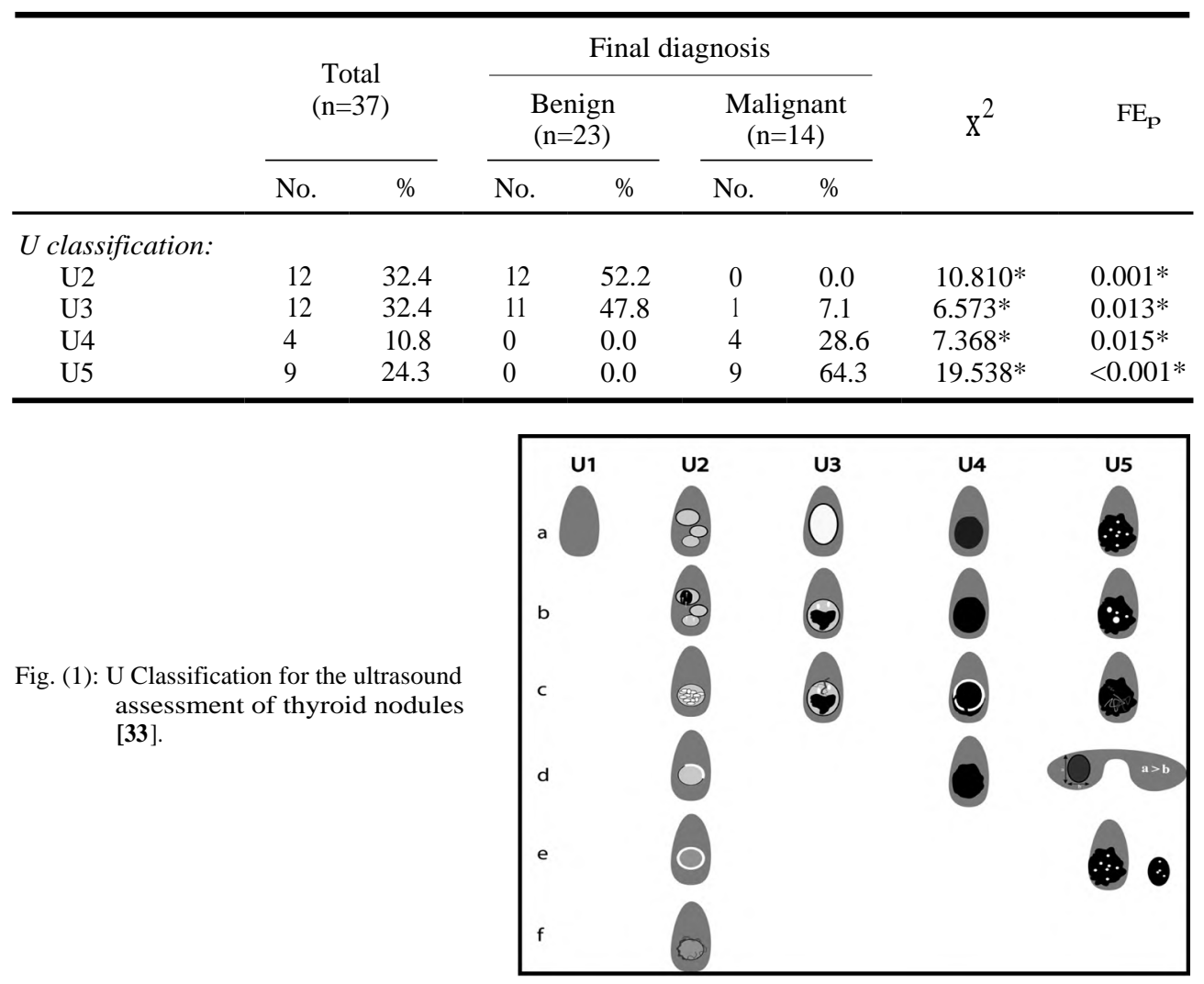
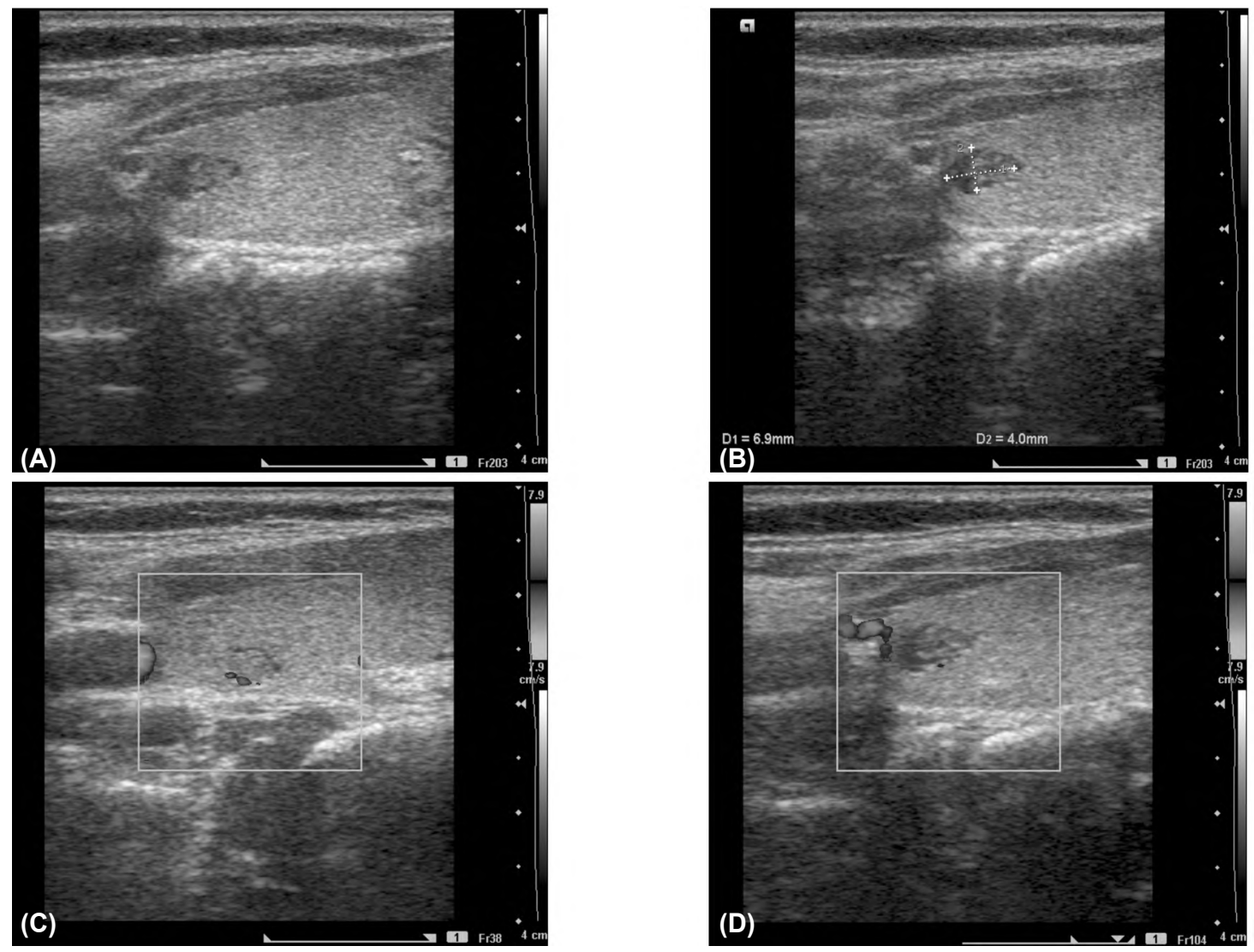

Fig. (2): (A) Transverse gray scale US shows right thyroid nodule of spongiform/micro-cystic nature. (B) Transverse gray scale US shows the nodule measurements $6.9 \times 4 \mathrm{~mm}$. (C,D) Transverse Color Doppler US shows peripheral vascularity. According to $\mathrm{U}$ classification system; it is a case of U2 type and the FNAC revealed Bethesda II. 

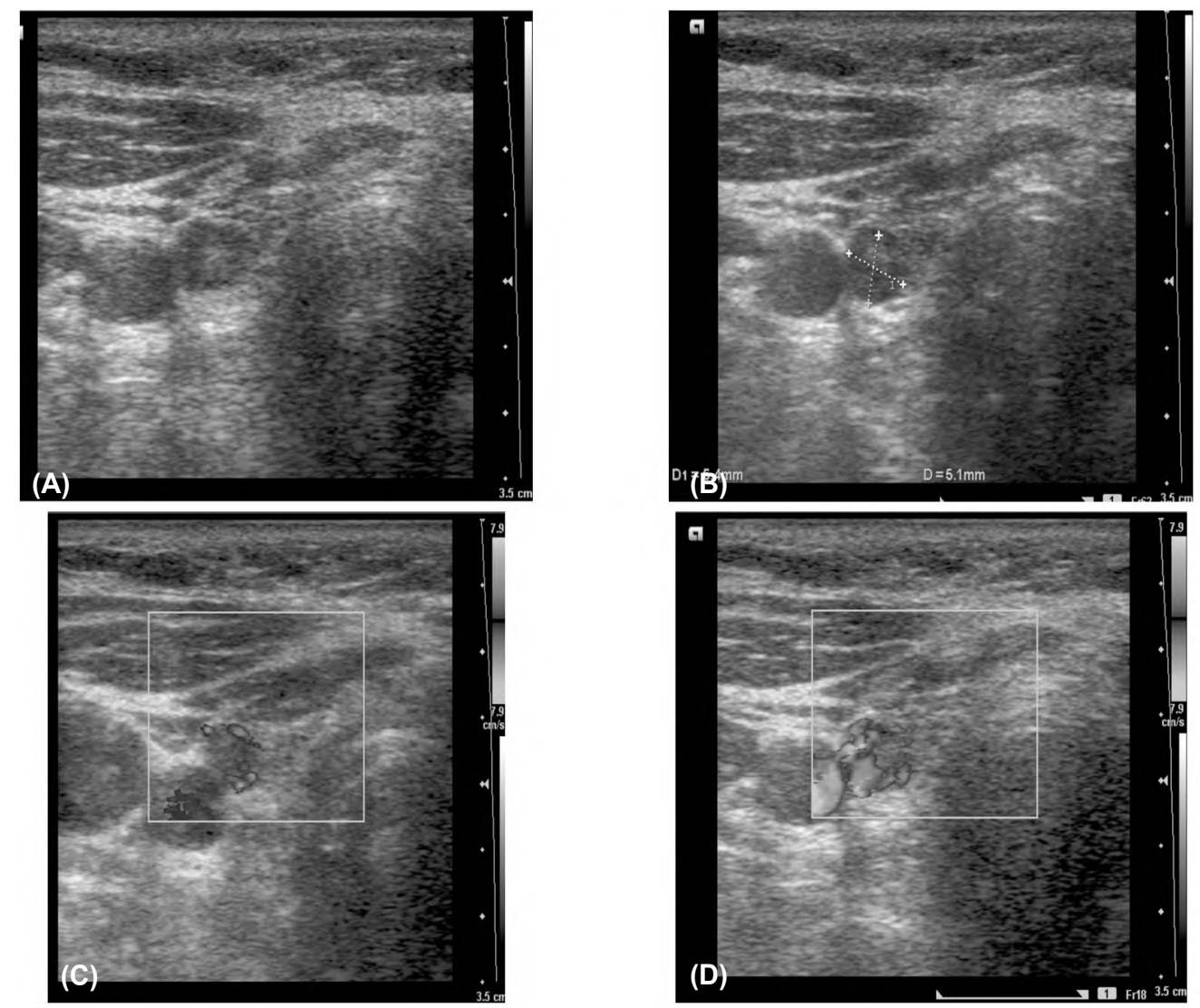

Fig. (3): (A) Transverse gray scale US shows a very hypoechoic solid thyroid nodule within the right thyroid lobe. (B) Transverse gray scale US shows the nodule measurements $5 \times 5 \mathrm{~mm}$. (C,D) Transverse Color Doppler US shows marked intra-nodular vascularity. According to U classification system; it is a case of U5 type and the FNAC revealed Bethesda IV.
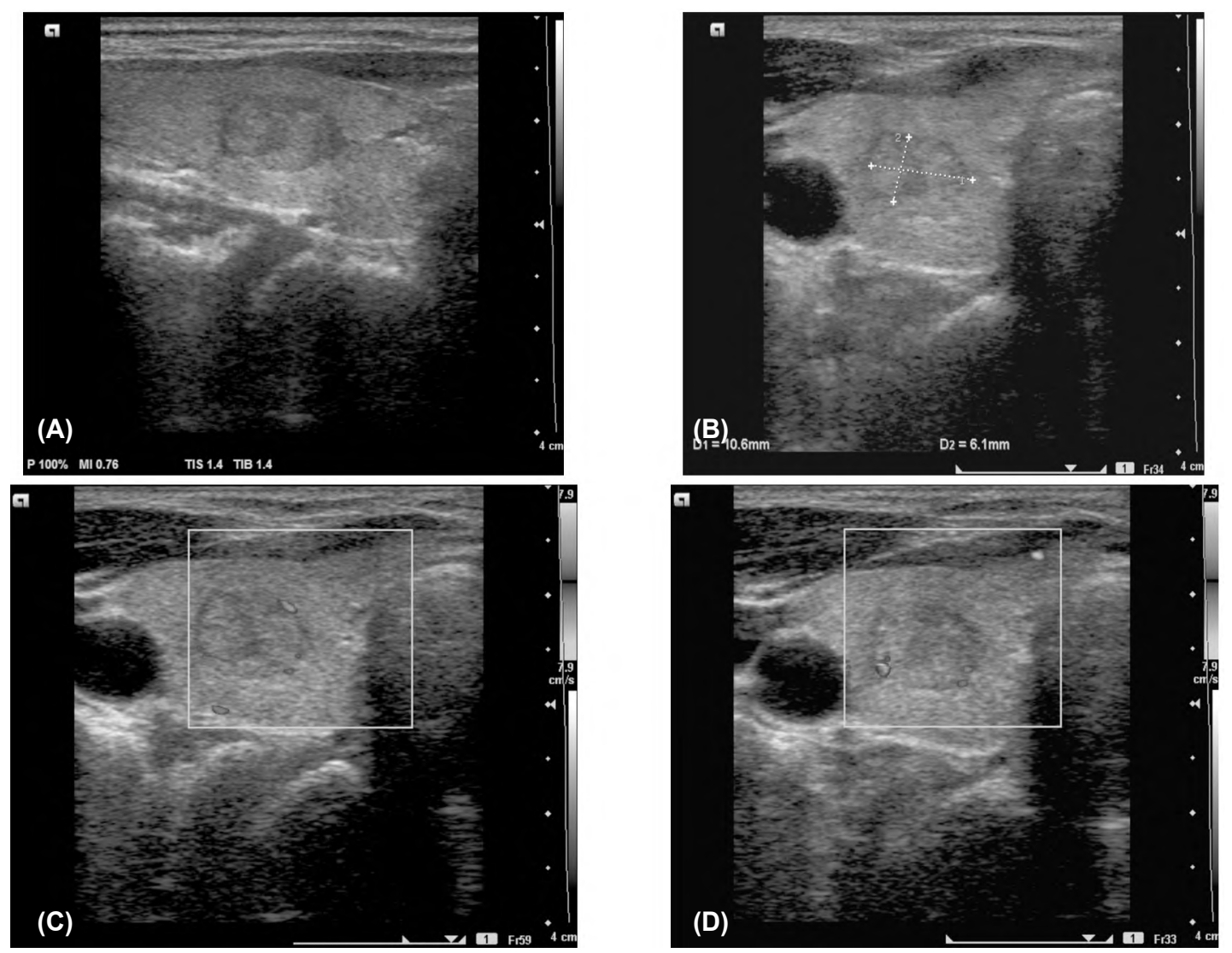

Fig. (4): (A) Transverse gray scale US shows an iso-echoic thyroid nodule within the right thyroid lobe of purely solid nature. (B) Transverse gray scale US shows nodule measurements $10.6 \times 6.1 \mathrm{~mm}$. (C,D) Transverse Color Doppler US shows peripheral vascularity. According to U classification system; it is a case of U2 type and the FNAC revealed Bethesda II. 

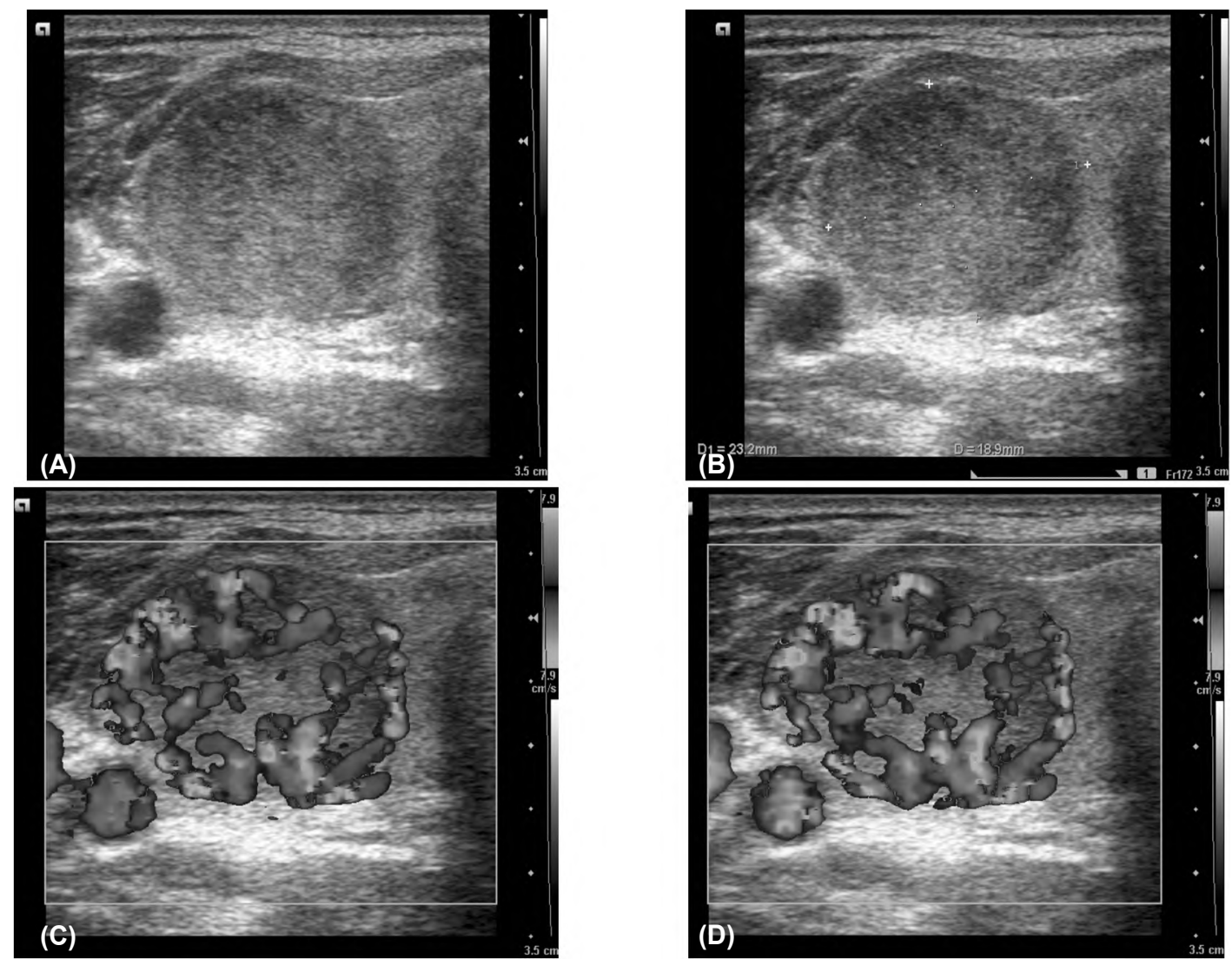

Fig. (5): (A) Transverse gray scale US shows homogenous very hypo-echoic thyroid nodule within the right thyroid lobe of purely solid nature. (B) Transverse gray scale US shows nodule measurements $2.3 \times 1.9 \mathrm{~cm}$. (C,D) Transverse Color Doppler US shows marked internal vascularity. According to U classification system; it is a case of U5 type and the FNAC revealed Bethesda V.
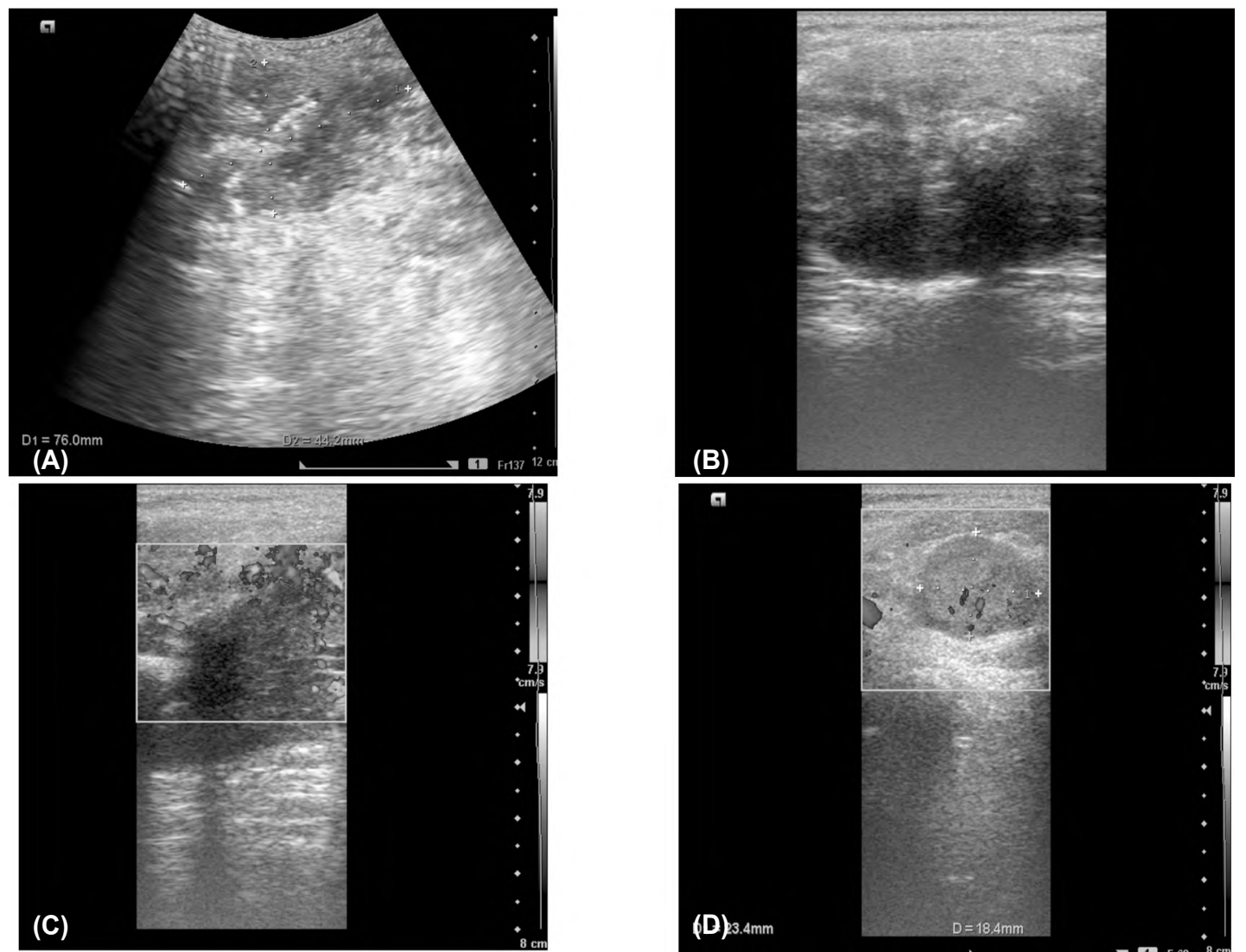

Fig. (6): (A) Longitudinal gray scale US shows a hypoechoic nodule within the left thyroid lobe of solid composition with taller than wider shape and its measurements $(7.6 \times 4.4 \mathrm{~cm})$. (B) Transverse gray scale US through the nodule shows the intra nodular micro-calcifications. (C) Transverse Color Doppler US shows intra-nodular vascularity. (D) Transverse gray scale US shows associated Sonographically suspicious lymph node. According to U classification system; it is a case of U5 type and the FNAC revealed Bethesda VI. 

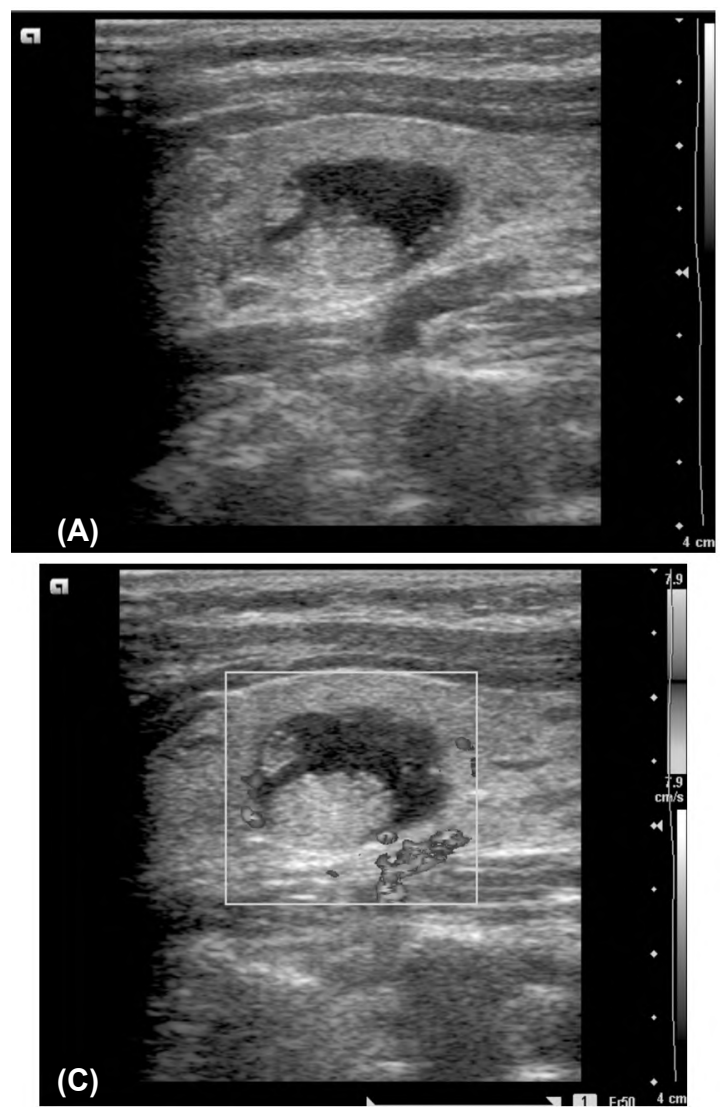
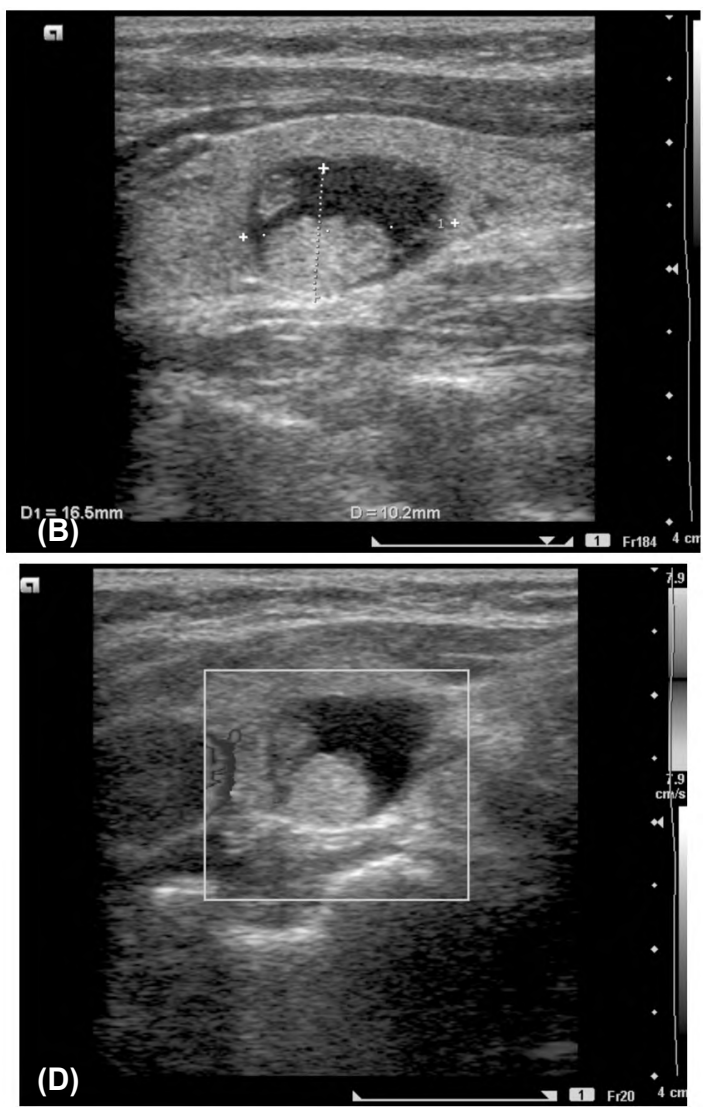

Fig. (7): (A) Transverse gray scale US shows homogenous mildly hyperechoic thyroid nodule within the right thyroid lobe of mixed solid/cystic nature. (B) Transverse gray scale US shows the measurements of the nodule $1 \times 1.6 \mathrm{~cm}$. (C,D) Transverse Color Doppler US shows mild peripheral vascularity. According to U classification system; it is a case of U2 type and the FNAC revealed Bethesda II.

\section{Discussion}

In the last few years, several studies have compared the different US risk stratifications systems in large cohorts of patients with thyroid nodules in order to evaluate the most accurate and useful image-classification system. The discussion is aimed to include the following headlines: (a) The discussion of distinctive US features of thyroid nodules and comparison to other studies, discussing them separately form an identified standard classification, (b) Review of literature regarding research work on BTA guidelines (c) Comparison of our study to other studies adopting the BTA (e) Mention of limitations of the study and possible recommendations. Demographics in our study revealed high female prevalence $(86.5 \%$ females compared to $13.5 \%$ males), agreeing with all researches. The incidence of malignancy in this study was high $(37.84 \%)$ as compared to highly variable researches $(4 \%-32 \%)$ [34-37].

Though not part of the scoring system, the size was measured as part of routine clinical practice. This is supported by Hoang et al., [38], Moon et al, [39] and Anil et al., [40], all stated that nodule size was not predictive of malignancy. The taller than wider shape shows statistical significance in our study for malignancy, matching with results stated by Frates et al., [41] and Park JM et al., [42]. The highest proportion $(=83.8 \%)$ had irregular/ lobulated margins, eight of them proved malignant nodules, while 6 nodules $(16.2 \%)$ had irregular/ lobulated margins, and all proved malignant. We found statistical significance of irregular/lobulated margins for malignancy. Ali A et al., [43] and Anil et al., [44] supported this sign as indicator of malignancy. However, Hoang et al., [38] and Moon et al., [45] mentioned that unless frank invasion beyond the thyroid capsule was demonstrated, the isolated US finding of irregular margins was an unreliable basis for depicting malignancy $[\mathbf{3 8 , 4 3 , 4 4 ]}$

Hyper-echogenicity was more suggestive of benignity, while hypo-echogenicity is assumed to be associated with more likelihood of a malignancy. These results were similar to what was mentioned by Brkljacic et al., [46] who stated that hypoechogenicity is associated with thyroid malignancy [46]. Also, these results are found to be in agreement with other literatures, that most of the malignant nodules are hypoechoic whilst most hyperechoic 
nodules are benign [47]. Also, it was stated by Anil et al., [44] who stated that decrease in echogenicity increased the risk for malignancy and Moon et al., [45] who mentioned that marked hypo-echogenicity is highly specific for malignant nodules by $92-$ $94 \%$. On the other hand, Iannuccilli et al., [48] reported no difference in hypo-echogenicity between benign and malignant nodules, though agreed on hyper-echogenicity as marker of benignity.

Results showed that all cystic nodules were benign, whilst $39.13 \%$ of solid nodules and $100 \%$ of mixed solid and cystic nodules were benign, and $60.87 \%$ of solid nodules were malignant. Finding of a purely solid nodule had statistical significance in our study for being malignant, yet this didn't totally agree with all the prior researches. Anil et al., [44], Phuttharak et al., [49] and Moon et al., [39] stated that finding of a solid component alone was not a reliable sign in differentiating malignant from benign nodules. In our study, although the two cystic nodules were benign, there was no statistical significance for benignity; this maybe attributed to the small number. We found all nodules with mixed solid/cystic composition were benign, and there was statistical significance for benignity. Frates et al., [41], Anil et al., [44] and Unnikrishnan et al., [50] stated that cystic and almost completely cystic nodules have a very low likelihood of being malignant. However, our finding regarding the mixed composition of a nodule was contradictory to Iannuccilli et al., [48] who stated that $11.8 \%$ and $11.1 \%$ of malignant and benign nodules respectively were mixed. Calcifications were seen in 7 nodules (18.9\%) and were according to their sites and shapes. In the current study, micro-calcifications were seen in 4 nodules $(10.8 \%)$, and coarse/globular calcifications were seen in 2 patients (5.4\%). Both micro- and globular calcifications had significance for malignancy. These findings are similar to those mentioned by Moon et al., [39] who reported that the presence of coarse calcification increased the risk of malignancy. Similarly, Hoang et al., [38] mentioned that coarse calcifications might coexist with microcalcifications in papillary cancers, and they were the most common type of calcification in medullary thyroid carcinomas. In contrast, Phuttharak et al., [48] and Anil et al., [44] stated that coarse calcification was more specific for benign nodules. In our study, a single benign nodule has "egg-shell" calcification. Although formerly considered a feature of benignity, Taki et al., [51] reported eggshell calcifications in thyroid cancers, mostly in papillary carcinoma and rarely in follicular carcinoma, whereas, Hoang et al., [38] stated that peripheral calcification was one of the patterns most commonly seen in a multinodular goiter but also might be seen in malignancy. Moon et al., [39] reported no significant difference between benign and malignant nodules having egg-shell calcification.

The vascularity of a thyroid nodule is checked up by color Doppler and categorized as absent, peripheral, central or mixed. In the current study, central/intra-nodular vascularity was deemed statistically as a significant indicator for malignancy. This contrasts Hoang et al., [38] whole stated that intra-nodal vascularity was nonspecific sign for depicting thyroid malignancy. He mentioned that more than $50 \%$ of hyper-vascular solid thyroid lesions were benign and that a peri-nodular flow, though commoner in benign nodules, was found in $22 \%$ of malignant ones.

This constellation of US findings have been grouped and categorized into multiple classification and scoring systems aiming at proper identification of most eligible nodule for FNAC, with avoidance of multiple unnecessary biopsies and surgeries, both imposing much economic burden. The TIRADS lesions has been intensively searched and widely adopted in multiple diagnostic centers worldwide, with emergences of multiple versions. The research literature is very rich in works trying to test reliability of each of them with comparison of multiple versions on large cohorts and under multi-disciplinary team-work. After the emergence of BTA since 2014, researches also were made to compare its diagnostic reliability with other lexicons of TIRADs, with yet many controversies, far beyond the scope of this limited articles $[\mathbf{5 2 , 5 3 , 5 4 ]}$

Investigating the BTA system enrolled variable testing methods in different fields, including the diagnostic yield and issues regarding the implementation during clinical practices. These included study of the lexicon as being incorporated into diagnostic algorithm of US nodules. Pantano et al., [55] studied the process of introduction and implementation of BTA guidelines into the reporting practice for Thyroid US at a large UK MDT center with a big group of sonographers performing thyroid US across multiple sites. There has been a gradual and steady increase in adaptive use of BTA guideline in reporting thyroid nodules, supposed to unify a more simplified "thyroid language" attributable to the easier user friendly. Another similar MDT-based single-center study by Grecian et al., [56] reported the early adoption of the of the guidelines through graded ultrasound reports in 57 patients with rich inter-departmental discussion, supporting safe discharge for U2 nodules, while 
U3 grading was common. Regional MDT discussion avoided 5 hemi-thyroidectomies.

Since US is operator-dependent, and thus is liable to many variances. Therefore, researches worked on inter-observer agreement. A study by Couzins et al., [57] found no statistically significant inter- or intra-observer variability in the U-scoring of thyroid nodules between 14 recruited participant US operators, thus reinforcing the validity of this scoring method in clinical practice and allaying concerns regarding potential subjective biases in reporting. A study by Weller et al., [58] revealed very good inter-observer agreement in using the BTA-U score amongst different observers at differing levels of expertise. They conducted work on a 73-patients sample examined by 5 observers and conducted that adherence to BTA-U scoring can potentially achieve $100 \%$ sensitivity in selecting malignant nodules for sampling.

Fariha et al., [59] revealed high very good reliability of BTA in predicting malignancy. Their retrospective cross-sectional study on 91 patients revealed that sensitivity, specificity, positive likelihood ratio, negative likelihood ratio, positive predictive value, negative predictive value and accuracy were $100 \%, 91.3 \%, 11.5,0.0,60 \%, 100 \%$ and $92.3 \%$, and $100 \%, 91.4 \%, 11.7 \%, 0.0,78.6 \%$, $100 \%$ and $93.5 \%$, for the non-conservative and conservative method of calculations respectively. Another parallel study conducted by Akhter et al., [60] on 100 patients revealed high sensitivity of the ultrasonography was $80 \%$ and specificity was $34 \%$. Moreover, positive predictive value was $100 \%$ and negative predictive value was found to be $90 \%$. Al-Chalabi et al., [61] conducted a large study on a huge patients cohort that enrolled 1,225 graded nodules in 964 patients, in trial to validate the usefulness of BTA throughout whole UK health system. Their results achieved high radiologypathology correlation with achieved $96.5 \%$ sensitivity, $93.7 \%$ specificity, and $93.9 \%$ accuracy. They used a pathology grading.

Rajan et al, [62] revealed that identification of thyroid nodules eligible for needle sampling was easier with the BTA classification, owing to userfriendly graphic references, used in clinical practice. They revealed good radiology-pathology in FNAC aspirates. Our study used a small cohort and showed limited statistics correlating radiology to limited FNAC aspirates similar to thus deduced by Rajan et al., [62] The U-classes showed very good to excellent significance when they were correlated to the pathology aspirates. Diagnostic accuracy couldn't be measured due to absence of a definite unified standard, particularly in absence of pathology grading and absence of thyroidectomies results.

The limitations of our study are multiple: Firstly, the small cohort of patients. Secondly, the study was uni-departmental and single center so feedback of thyroidectomies couldn't be obtained. Thirdly, the proposed BTA was not compared to other lexicons. Fourth, the usual limitations of US as being a "operator dependent" technique and we recruited a single observer. Fifth, exclusion of multi-nodular pathologies which show high prevalence, and yet this is explained in methodology section. Recommendations are directed for further researches to be made on larger series with multiple comparisons of multiple variants of TIRADS with BTAs. This needs sophisticated statistics and prolonged efforts that may enroll a large multidisciplinary working team. BTA is suggested and recommended to be tried in more national imaging centers and that graphics of the lexicon shall preferably be put in each US unit and that reporting would use the BTA in combination with TIRADs. Nation-wise, feedbacks from pathology shall enhance the experience of the radiologist in UScharacterization of nodules, thus evading unnecessary FNA biopsies. World-wise, global efforts should be exerted to unify these different risk stratification systems practiced throughout the whole imaging world.

\section{Declarations:}

Ethics Approval and Consent to Participate: All procedures followed were in accordance with the ethical standards of the responsible committee on human experimentation (Institutional Review Board (IRB)" of Alexandria General Hospital on 14th February 2017) and with the Helsinki Declaration of 1964 and later versions. Committee's reference number is unavailable (NOT applicable). No consent was obtained from the patients since it was a retrospective study.

Consent for publication: This was not needed, as the study is "retrospective".

Availability of data and materials: The datasets used and/or analyzed during the current study are available from the corresponding author on reasonable request.

Competing interests: The authors declare that they have no competing interests.

Funding: This study had no funding from any resource. 
Authors' contributions: LE provided the cases and final diagnoses, with detaileddescription of results. MS gave the idea, wrote the section of introduction and NE provided the whole references for introduction while ME wrote discussion with making of figure legends, DA provided pathology of aspirates. NA collected and archived all cases.

\section{References}

1- WOLINSKI K., SZKUDLAREK M., SZCZEPANEKPARULSKA E. and RUCHALA M.: Usefulness of different ultrasound features of malignancy in predicting the type of thyroid lesions: A meta-analysis of prospective studies. Pol. Arch. Med. Wewn, 124: 97-104, 2014.

2- RAHIMI M., FARSHCHIAN N., REZAEE E., SHAHEBRAHIMI K., MADANI H.: To differentiate benign from malignant thyroid nodule comparison of sonography with FNAC findings. Pak J. Med. Sci., 29:77-80, 2013.

3- PAPINI E., GUGLIELMI R., BIANCHINI A., CRESCENZI A., TACCOGNA S. and NARDI F.: Risk of malignancy in nonpalpable thyroid nodules: Predictive value of ultrasound and color-Doppler features. J. Clin. Endocrinol. Metab., 87: 1941-1946, 2002.

4- RORIVE S., D'HAENE N.., FOSSION C., DELPIERRE I., ABARGUIA N. and AVNI F.: Ultrasound-guided fineneedle aspiration of thyroid nodules: stratification of malignancy risk using follicular proliferation grading, clinical and ultrasonographic features. Eur. J. Endocrinol., 162: 1107-15, 2010.

5- KWAK J.Y., HAN K.H., YOON J.H., MOON H.J., SON E.J. and PARK S.H.: Thyroid imaging reporting and data system for US features of nodules: A step in establishing better stratification of cancer risk. Radiology, 260: 8929, 2011.

6- RANDOLPH G.W.: The Thyroid Gland. In: Randolph, G.W., Ed., Surgery of the Thyroid and Parathyroid Glands, Vol. 1, Elsevier Sanders, Philadelphia, 2 nd Edition, 702. https://doi.org/10.1007/BF00284951, 2013.

7- ELSHEIKH H., SHALAAN A. and ELSEBAEY D.: Role of Ultrasound and Color Doppler in Assessment of Incidental Thyroid Nodules. Benha Medical Journal, Vol. 38, Special Issue (Radiology), 64-75, 2021.

8- DAVIES L. and WELCH H.G.: Current thyroid cancer trends in the United States JAMA Otolaryngol. Head Neck Surg., 140: 317-22, 2014.

9- GHARIB H., PAPINI E. and GARBER J.R.: American Association of Clinical Endocrinologists, American College of Endocrinology, And Associazione Medici Endocrinologi Medical Guidelines for Clinical Practice for The Diagnosis And Management of Thyroid NodulesUpdate. Endocr. Pract, 22: 622-39, 2016.

10- HORVATH E., MAJLIS S., ROSSI R., FRANCO C., NIEDMANN J.P. and CASTRO A.: An ultrasonogram reporting system for thyroid nodules stratifying cancer risk for clinical management. J. Clin. Endocrinol. Metab., 94: 1748-51, 2009.

11- HAMBLY N.M., GONEN M., GERST S.R., LI D., JIA $X$. and MIRONOV S.: Implementation of evidence-based guidelines for thyroid nodule biopsy: A model for estab- lishment of practice standards. AJR Am. J. Roentgenol., 96: 655-60, 2011.

12- ANDRIOLI M., CARZANIGA C. and PERSANI L.: Standardized ultrasound report for thyroid nodules: The endocrinologist's viewpoint. Eur. Thyroid J., 2: 37-48, 2013.

13- KOH J., KIM S.Y., LEE H.S., KIM E.K., KWAK J.Y., MOON H.J.: Diagnostic performances and interobserver agreement according to observer experience: A comparison study using three guidelines for management of thyroid nodules. Acta. Radiol., 59: 917-23, 2018.

14- PARK J.W., KIM D.W., KIM D., BAEK J.W., LEE Y.J. and BAEK H.J.: Korean Thyroid Imaging Reporting and Data System features of follicular thyroid adenoma and carcinoma: A single-center study. Ultrasonography, 36: 349-54, 2017.

15- TESSLER F.N., MIDDLETON W.D. and GRANT E.G.: ACR Thyroid Imaging, Reporting and Data System (TIRADS): White Paper of the ACR TI-RADS Committee. J. Am. Coll. Radiol., 14: 587-95, 2017.

16- RUSS G., BIGORGNE C. and ROYER B.: The Thyroid Imaging Reporting and Data System (TIRADS) for ultrasound of the thyroid. J. Radiol., 92: 701-13, 2011.

17- RUSS G., ROYER B., BIGORGNE C.: Prospective evaluation of thyroid imaging reporting and data system on 4,550 nodules with and without elastography. Eur. J. Endocrinol., 168: 649-55, 2013.

18- RUSS G., BONNEMA S.J. and ERDOGAN M.F.: European Thyroid Association Guidelines for Ultrasound Malignancy Risk Stratification of Thyroid Nodules in Adults: The EU-TIRADS. Eur. Thyroid J., 6: 225-37, 2017.

19- CANTISANI V., GRAZHDANI H. and DRAKONAKI E.: Strain US Elastography for the Characterization of Thyroid Nodules: Advantages and Limitation. Int. J. Endocrinol., 2015: 908575, 2015.

20- SHIN J.H., BAEK J.H. and CHUNG J.: Ultrasonography diagnosis and imaging-based management of thyroid nodules: Revised Korean Society of Thyroid Radiology consensus statement and recommendations. Korean J. Radiol., 17: 370-95, 2016.

21- KOH J., KIM S.Y., LEE H.S., KIM E.K., KWAK J.Y. and MOON H.J.: Diagnostic performances and interobserver agreement according to observer experience: A comparison study using three guidelines for management of thyroid nodules. Acta. Radiol., 59: 917-23, 2018.

22- SÁNCHEZ J.F.: TI-RADS classification of thyroid nodules based on a score modified according to ultrasound criteria for malignancy. Rev. Argent. Radiol., 78 (3): 138-148, 2014.

23- MAHAJAN A., VAIDYA T., VAISH R. and SABLE N.: The Journey of Ultrasound based Thyroid Nodule Risk Stratification Scoring Systems: Do All Roads Lead to Thyroid Imaging, Reporting and Data System (TIRADS)? Journal of Head \& Neck Physicians and Surgeons, 5 (2): 57-65, 2017.

24- KYRIACOU1 A., VOGIAZANOS E. and GHATTAMANENI S.: A Critical Reflection of British Thyroid Association (BTA) Guidelines for the Management of Thyroid Nodules and Cancer Thyroid Disorders Ther., 5 (2): 1-3, 2016. 
25- DENG X.H., TANG L.N. and LIU S.Q.: A Proposal to Stratify the Intermediate-Risk Thyroid Nodules According to the AACE/ACE/AME Guidelines with Ultrasound Features. Sci. Rep., 7: 17901, 2017.

26- XIE Ch., COX P., TAYLOR N. and LaPORTE S.: Ultrasonography of thyroid nodules: A pictorial review Insights Imaging, 7 (1): 77-86, 2016.

27- LINGAM R.K., QARIB M.H. and TOLLEY N.S.: Evaluating thyroid nodules: Predicting and selecting malignant nodules for fine-needle aspiration (FNA) cytology. Insights Imaging, 4 (5): 617-24, 2013.

28- FLORIDI C., CELLINA M. and BUCCIMAZZA G.: Ultrasound imaging classifications of thyroid nodules for malignancy risk stratification and clinical management: state of the art. Gland Surg., 8 (3): 233-44, 2019.

29- ARAMBEWELA M., WIJESINGHE A., RANDHAWA K., BULL M., WADSLEY J. and BALASUBRAMANIAN S.P.: A pragmatic assessment of the British Thyroid Association "U classification" of thyroid nodules with a focus on their follow-up. Clinical Radiology, 75 (6): 46673, 2020.

30- HAMBLY N.M., GONEN M., GERST S.R., LI D., JIA $X$. and MIRONOV S.: Implementation of evidence-based guidelines for thyroid nodule biopsy: A model for establishment of practice standards. AJR Am. J. Roentgenol., 196: 655-60, 2011.

31- HAUGEN B.R., ALEXANDER E.K. and BIBLE K.C.: 2015-American Thyroid Association Management Guidelines for Adult Patients with Thyroid Nodules and Differentiated Thyroid Cancer: The American Thyroid Association Guidelines Task Force on Thyroid Nodules and Differentiated Thyroid Cancer. Thyroid, 26: 1-133, 2016.

32- YOON J.H., LEE H.S. and KIM E.K.: Malignancy Risk Stratification of Thyroid Nodules: Comparison between the Thyroid Imaging Reporting and Data System and the 2014 American Thyroid Association Management Guidelines. Radiology, 278: 917-24, 2016.

33- PERROS P., BOELAERT K. and COLLEY S.: Guidelines for the management of thyroid cancer. Clin. Endocrinol., 81 (1): 1-122. Graph Reference, 2014.

34- KUNG A.W., CHAU M.T. and LAO T.T.: The effect of pregnancy on thyroid nodule formation. J. Clin. Endocrinol. Metab., 87 (3): 1010-4, 2002.

35- STRUVE C.W., HAUPT S. and OHLEN S.: Influence of frequency of previous pregnancies on the prevalence of thyroid nodules in women without clinical evidence of thyroid disease. Thyroid, 3 (1): 7-9, 1993.

36- HEGEDUS L.: Clinical practice The thyroid nodule. N. Engl. J. Med., 351: 1764-71, 2004.

37- CAPPELLI C., PIROLA I., CUMETTI D., MICHELETTI L., TIRONI A. and GANDOSSI E.: Is the antero-posterior and transverse diameter ratio of non-palpable thyroid nodules a sonographic criteria for recommending fine needle aspiration cytology? Clin. Endocrinol., 63: 68993, 2005.

38- HOANG J.K., LEE W.K., LEE M., JOHNSON D. and FARRELL S.: US features of thyroid malignancy: Pearls and pitfalls1. Radiographics, 27: 847, 2007.

39- MOON W.J., BAEK J.H., JUNG S.L., KIM D.W., KIM E.K. and KIM J.Y.: Ultrasonography and the ultrasound- based management of thyroid nodules: consensus statement and recommendations. Korean Journal of Radiology, 12: 1-14, 2011.

40- ANIL G., HEGDE A. and CHONG F.H.: Thyroid nodules: Risk stratification for malignancy with ultrasound and guided biopsy. Cancer imaging: The official publication of the International Cancer Imaging Society, 11: 209-23, 2011.

41- FRATES M.C., BENSON C.B., CHARBONEAU J.W., CIBAS E.S., CLARK O.H. and COLEMAN B.G.: Management of thyroid nodules detected at US: Society of Radiologists in Ultrasound consensus conference statement. Radiology, 237: 94-800, 2005

42- PARK J.M., CHOI Y. and KWAG H.J.: Partially cystic thyroid nodules: Ultrasound findings of malignancy. Korean J. Radiol., 13 (5): 530-5, 2012.

43- AMER A.M. ALI, ABDULKADER H. HASAN and TAHIR A. HAWRAMI: The role of conventional ultrasound in theassessement of the thyroid nodules in Al-Sulaimanyia territory. Bas J. Surg., 15: 34, 2009.

44- ANIL G., HEGDE A. and CHONG F.H.: Thyroid nodules: risk stratification for malignancy with ultrasound and guided biopsy. Cancer imaging: The official publication of the International Cancer Imaging Society, 11: 209-23, 2011.

45- MOON W.J., JUNG S.L., LEE J.H., NA D.G., BAEK J.H. and LEE Y.H.: Benign and malignant thyroid nodules: US differentiation-multicenter retrospective study. Radiology, 247: 762-70, 2008.

46- BRKLJACIC B., CUK V., TOMIC-BRZAC H., BENCEZIGMAN Z., DELI-BRKLJACI D. and DRINKOVI I.: Ultrasonic evaluation of benign and malignant nodules in echographicallymultinodular thyroids. J. Clin. Ultrasound, 22: 71-76, 1994.

47- NAYAR R. and NEMCEK A.: Radiologic and pathologic features of thyroid calcifications: A viewpoint. Pathology case review, 8: 22-4, 2003.

48- IANNUCCILLI J.D., CRONAN J.J. and MONCHIK J.M.: Risk for malignancy of thyroid nodules as assessed by sonographic criteria the need for biopsy. Journal of Ultrasound in Medicine, 23: 1455-64, 2004.

49- PHUTTHARAK W., SOMBOONPORN C. and HONGDOMNERN G.: Diagnostic performance of gray-scale versus combined gray-scale with colourdoppler ultrasonography in the diagnosis of malignancy in thyroid nodules. Asian Pac. J. Cancer Prev., 10: 759-64, 2009.

50- UNNIKRISHNAN A.G.: Nodular diseases in the thyroid The Journal of the Association of Physicians of India, 59 (Suppl): 43-5, 2011.

51- TAKI S., TERAHATA S., YAMASHITA R., KINUYA K., NOBATA K. and KAKUDA K.: Thyroid calcifications: Sonographic patterns and incidence of cancer. Clinical Imaging, 28: 368-71, 2004.

52- MISTRY R., HILLYAR C.H., NIBBER A., SOORIYAMOORTHY S.A. and KUMAR N.: Ultrasound Classification of Thyroid Nodules: A Systematic Review. Cureus 12 (3): 27239: 1-8, 2020.

53- CHNG C., TAN H., TOO C., LIM W., SZECHIAM P., ZHU L., NADKARNI N. and LIM A.: Diagnostic per- 
formance of ATA, BTA and TIRADS sonographic patterns in the prediction of malignancy in histologically proven thyroid nodules Singapore Med. J., 59 (11): 578-83, 2018

54- GOPALAN P., SINGH S., VAIDYANATHAN S., KARTHIK S. and LEEDS U.K.: Compliance of British Thyroid Ultrasound "U" Guidelines-Are we all speaking the "Unified" Thyroid language? Poster presented at Eduactaional exhibits in proceedings of European Congress of Radiology-ECR Vienna, Austria, 2016.

55- PANTANO L., MADDALONI E., BRIGANTI1 S., ANGUISSOLA G., PERRELLA E., TAFFON E., PALERMO A., POZZILLI P., MANFRINI S. and CRESCENZI A.: Differences between ATA, AACE/ACE/AME and ACR TI-RADS ultrasound classifications performance in identifying cytological high-risk thyroid nodules. European Journal Endocrino., 178 (6): 595-603, 2018.

56- GRECIAN S.H., HERLIHY O., FERRANDO L., STRACHAN M., PATEL1 D. and WILLIAMSON R.: Adoption of the British Thyroid Association guidelines for the investigation of thyroid nodules: A district general hospital experience. Endocrine Abstracts, 50 P410, 2017.

57- COUZINS M., FORBES S., VIGNESWARAN G., MITRA I. and RUTHERFORD E.: Ultrasound grading of thyroid nodules using the BTA U-scoring guidelines - Is there evidence of intra-and inter-observer variability? Ultrasound, 0 (0): 1-6, 2020.
58- WELLER A., SHARIF B., QARIB M., ST LEGER D., De SILVA H. and LINGAM R.: British Thyroid Association 2014 classification ultrasound scoring of thyroid nodules in predicting malignancy: Diagnostic performance and inter-observer agreement. Ultrasound, 28 (1): 4-13, 2020.

59- ABDGHANI F., ISA N., HARUNARASHID H., SUHAIMI S. and SRIDHARAN R.: Reliability of the ultrasound classification system of thyroid nodules in predicting malignancy. Med. J. Malaysia, 73 (1): 9-15, 2018.

60- AKHTER T., SHAHID K. and AFZAL U.: Diagnostic Accuracy of Ultrasound U Classification System of Thyroid Ultrasound in Predicting Thyroid Malignancy by Using Histopathology as Gold Standard. Ann. Pak. Inst. Med. Sci., 222: 6, 2018.

61-AL-CHALABI H., KARTHIK S. and VAIDYANATHAN: Radiologicalepathological correlation of the British Thyroid Association ultrasound classification of thyroid nodules: A real-world validation study Clinical Radiology, 74: 702-11, 2019

62- RAJANRAJAN P., BARBER C. and ARKOUMANI E.: Pictorial essay of thyroid nodules using the British Thyroid Association Ultrasound classification with radio pathological correlation. Clinical Radiology, 70 (51): 1-9, 2015.

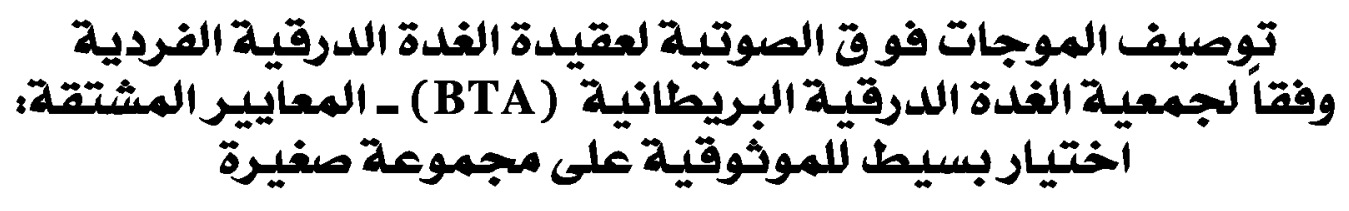

$$
\begin{aligned}
& \text { الخلفية: تم استخدام معاجم تصوير الغدة الدرقية في الولايات المتحدة على نطاق واسع في الممارسة السريرية لتصديد عقيدات الغدة }
\end{aligned}
$$

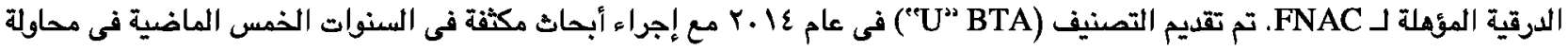

$$
\begin{aligned}
& \text { لاختيار جدواها وموثقيتها فى التقسيم الطبقى للعقيدات الدرقية في الولايات المتحدة. }
\end{aligned}
$$

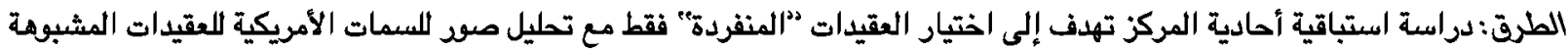

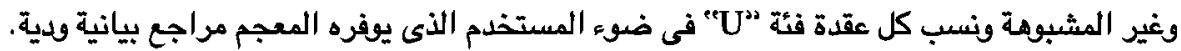

$$
\begin{aligned}
& \text { النتائج: تم اختيار مجموعة صغيرة، من Vr عقدة انفرادية، من إجمالى •lo مقارنة بنتيجة فحص الخلايا الطموحة FNAC وفقاً لتدريج }
\end{aligned}
$$

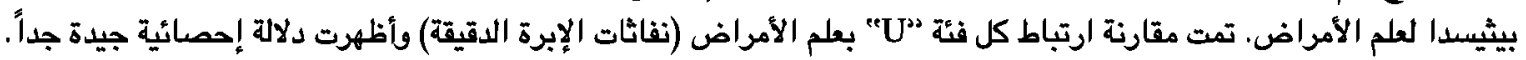

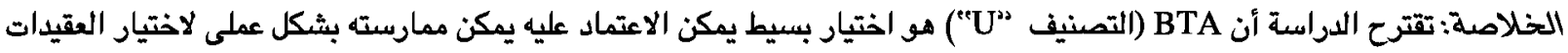

$$
\begin{aligned}
& \text { المؤهلة لـ FNAC بين الغدلد متعددة العقيدات. }
\end{aligned}
$$

